\title{
14
}

\section{State of the Art in Information Technology in Educational Management in the Czech Republic}

\author{
J. Vaníček and A. Nohejlováb \\ a Institute for Informatics in Education, Senovážné náměstí 26, Prague 1, Czech Republic \\ ${ }^{\mathrm{b}}$ Ministry of Education, Youth and Physical Training of the Czech Republic, Karmelitskí 7 , \\ Prague 1, Czech Republic
}

\begin{abstract}
Some basic information concerning education in the Czech Republic from the point of view of information and management system is given. The problems of the interface between local schools information systems and the central system as a part of the Statc Information System are discussed. The role of the Czech Educational and Scientific Network (CESNET) in educational management is described.
\end{abstract}

Keyword Codes: K.3.0; K.3.1; C.2.0

Keywords: Computers and Education, General; Computer Uses in Education; Computer Communication Networks, General

\section{INTRODUCTION}

Even though the Czech Republic only in arose the break-down of Czechoslovakia after January 1993, the Czech State, its culture and its educational system have a long history.

The first schools in our country, in the 9th and 10th centuries, werc church schools attached to monasteries. Records of secular schools date back to the 13th century. In the 14th century, under the reign of the Czech King and Roman Empcror Charles IV, Praguc was a European cultural center. In 1348 Charles IV founded Charles University, the oldest European university north of the Alps. Jan Amos Comenius, the great Czech philosopher, theologian and educationalist of the seventeenth century, is also known as a teacher of nations.

Education has always played a serious role in the history of our nation. Neither the Nazis, nor the communists were able to devastate our educational system, cven though they damaged it considerably. Of course, there is much to be reformed, but from the international point of view education in the Czech Republic is on a fairly good level [1]. In the age category from 15 to 64 , about $8 \%$ of the population has university education, $63 \%$ upper secondary education, and $28 \%$ lower secondary education; only $1 \%$ has not finished secondary education. The rather low percentage of people with higher education can be explained by the fact that our country has so far not had any post-secondary education except for universities. Schools corresponding for example to the German Fachhochschule have been experimental only. 
Voluntary kindergartens are attended by children from 3 to 5 years. Compulsory education is up to 16 years, starting at 6 . The first eight years usually consist of basic (elementary) school which has two grades, with continuation either in the so called gymnasium (high school), which prepares students directly for further university studics, or in a specialised upper secondary school, or in a secondary vocational school, which can take 2, 3 or 4 years. Gymnasiums, specialised upper secondary schools and four-ycar secondary vocational schools are fully comparable with colleges in the USA and they are completed with the so-called Maturity certificate after which students can continuc their studies at a university. About $50 \%$ of secondary students obtain this certificatc.

This sector of the educational system is administered regionally by means of 85 local school authorities for single districts. Districts have usually about 50 to 300 thousand inhabitants. Greater schools have full legal independence and the district authority allocates them money from the state budget only. Smaller schools are directly managed by the school authorities.

Since 1990, a number of private, church or municipal schools have one's rise. These schools can collect school-fees or special allowances. The state, however, equally contributes to pupils of all types of schools, including private ones. School-fecs serve only for improvement of education above the current standard.

The educational system is very liberal regarding the curriculum and the pedagogical methods used. But there are exceptions; for example, eight-year gymnasiums for gifted children starting from age ten.

In the Czech Republic there are 23 universities (from Charles University which is the largest with approximately 20,000 students, to small art universities). The universitics comprise 104 faculties. Faculties are relatively independent of the university management. More than 109,000 students are at our universities at present. The typical minimal period of studies is: three years for the bachelor's degree, five years for the master's degrec, and eight years for the doctoral degree. Universities are quite independent, their management is elected by the academic community and the state does not interfere in their activities, with the exception of the accreditation for awarding academic degrecs and of the allocation of funds from the state budget which is gencrally done according to number of students.

\section{EDUCATIONAL MANAGEMENT}

At present a broad liberalisation of the educational system is in progress, regarding both the curriculum and interior organisation and management of schools. The state supports the principle that everything is to be decided at the lowest possible competent level.

On the other hand, as all schools, including the church and the private ones, are predominantly financed from the state budget it is necessary at a time of economic transformation, to manage the means very carefully, but equitably.

This situation puts heavy demands on the educational information system. On the central level, it is necessary to collect and evaluate performance data of all schools and educational facilities for state statistics and for ministerial decisions. This involves not only numbers of teachers, students and pupils, but also all other factors influencing the budget, the financial demands of the subject of study, and for example the specific geographical conditions of a school, numbers of handicapped children integrated, cte. 
Regarding the independence of schools, each school has a right to buy a hardware and software for its purpose separately. Therefore the hardware and softwarc of various institutions is very diversified. Some products for internal management may be centrally recommended and supported but they are not compulsory.

On the levels primary and secondary the schools and local school authorities use various program tools ranging from common word processors, spreadsheets, special programs for evaluating the pupils' results including certificate printing, up to relativcly sophisticated programs for timetabling. It is of interest that although this latter task is an NP-complete problem and, therefore cannot be solved in a practical way for a non-trivial volume of data, we have reached some success in assembling heuristic and user friendly systems, which work on the principle of man-machinc co-opcration, combining intuitive human decision with the complete monitoring and possible collision control contributed by the computer. The central level support the program system of staff and wages linked to the finance management of the school and the compulsory deliveries to social and health insurance funds. This system is very adequate, and its maintenance provides the possibility of immediate reaction to frequent changes in the laws.

At universities faculties usually create their own information systems. They are as a rule complex systems, often developed by CASE-tools. Owing to the considerablc differences in organisation of the individual faculties the created information systems mutually differ substantially. Some of such systems are not finished yet. In general. problems arise from insufficient co-operation between the information systems of the individual faculties and in adequate interface with the central information system for decisions on government level.

The Central Data Base for the educational system is managcd by the Institute for Informatics in Education (IIE) which is also the only reporting place in the education branch towards state statistics. The Institute also insures the methodology of the data flow, defines the interface for the data transfer among subjects, and maintains the Educational Data Base.

At present the Educational Data Base in the IIE comprises 21 sub-bases of performances of schools and their employees, and their wage means in the total range of about 500 MByte, including 48 educational and state code-books. The data base is operated and maintained by a team of about 25 employees within the local LANTASTIC network of computers of very different performance types, compatible with the IBM PC standard.

The base stores updated data on more than 25,000 subjects (schools and educational facilities) and 104 university faculties and 45 other educational organisations. In the casc of regional educational system the data are collecting through the mediation of 85 local educational authorities. As the level of technology used by reporting institutions as well as the qualifications of persons working with data are since very different, the greatest problem is the observance of the defined interface of transferred data and their validity and consistency. The IIE tries to improve this by developing and supplying softwarc that make it possible to perform as many controls as possible directly at the reporting place before sending data to the center. The situation is not yet fully satisfactory because not all institutions use these tools.

Because the data in the central information system are a single source for finance allocation from the state budget to schools, no incomplete inquiry is sufficient. 
The actual communication with the regional educational system is carried out by means of floppy disks (roughly $90 \%$ ) and paper forms $(10 \%)$. Communication by means of INTERNET network is just starting. In higher education, most of the data arc transferred through the INTERNET network which is described in the following section.

To conclude of this section, we will briefly mention other roles of the IIE.

Besides the collection of statistics and management educational information, the other roles of the IIE are:

- to get and to publish information concerning educational organisation and management in other countries and pedagogical methods applied there

- to support the utilisation of information technologies at all levels of education and to help teachers with the choice of hardware and software, and with the creation of educational software or multimedia teaching applications.

IIE also includes the State Pedagogical Comenius Library, the public library which with its fund of approximately half a million books is the Central State Scientific Library for pedagogy and education, the Collection Fund of text books including old prints of high historic value, and the Methodical Centre for the network of libraries in the Czcch educational system. This library also includes the Czech National Centre for the European Database of the Pedagogical Research EUDISED. Using the pedagogical thesaurus and computer technology, the records of a pedagogical research in the Czcch Republic arc procesed there, to suply the EUDISED database. On the other hand, from the EUDISED database information is acquired for our specialists.

\section{CESNET (Czech Educational and Scientific NETwork)}

At the moment, users in the Czech Republic can directly access the following Wide Area Computer Networks:

- EARN, the European Academic and Research Network with ten nodes plays an important role in our Wide Area Networking. On CSEARN (the Czech and Slovak EARN node) at the Czech Technical University Computing Centre in Prague the NETSERV, LITSERV and other standard EARN/BITNET services are supported as well as an EARN INTERNET E-mail gateway.

- EUnet, a network of Unix-based computers, has 19 nodes and is used mostly at commercial institutions. Dial-up links are used, E-mail and electronic conferences are supported.

- FIDONET, a network of MS-DOS based personal computers, which however lies outside the scope of this article.

- INTERNET, the world-wide "network of networks" which uscs TCP/IP communication protocols and provides some services not available in other networks (remote login, ctc.) is the most attractive for our users.

At the end of 1991, the Czech government institutions in the educational sphere proposed the creation of a common infrastructure for the whole academic and research community in the former Czechoslovakia. The Federal project FESNET was accepted in the spring of the year 1992. After Czechoslovakia was divide into the Czech Republic and the Slovak Republic, FESNET was divided into two independent parts: CESNET and SANET (Slovak Academic Network). The CESNET backbone has been operated since February 1993. 
The INTERNET TCP/IP protocols are also acceptable for many EARN and EUnct computers and so they have been selected as the basic protocols of the academic network. The CESNET backbone can carry additional communication protocols (ApplcTalk, DECnet, IPX, X.25, etc.) because multiprotocol routers are used at the CESNET backbonc and at all CESNET nodes (CISCO routers have been selected).

The CESNET project tried to select the communication media with the best price/performance ratio. Various technologies (satellite, microwave, terrestrial links) have been considered by tenders from several suppliers. Main links allow $64 \mathrm{~kb} / \mathrm{s}$, scveral minor locations are interconnected by digital or analog $19.2 \mathrm{~kb} / \mathrm{s}$ links.

The CESNET backbone connects all main 15 Czech and Moravian university cities.

A part of the CESNET backbone is a metropolitan Prague Academic Network, PAS, which contains $20 \mathrm{CISCO}$ routers in various Prague universities, main libraries, in the Czech Academy of Science, the Ministry of Education, Youth and Physical Training and also in the Institute for Informatics in Education. The situation is similar in the Moravian capital Brno.

The administration of each campus-wide or academic metropolitan network (with hundreds or thousands of hosts) connected to the CESNET will be responsible for monitoring and managing their own traffic. Network management programmes using the SNMP protocol (PSI SNMP version 4.1) running mostly in the SUN workstations are used.

The CESNET is already using the following international links:

- Prague - Vienna (EBONE, Austria, $128 \mathrm{~kb} / \mathrm{s}$ )

- Prague - Bonn (DFN, Germany, $64 \mathrm{~kb} / \mathrm{s}$ )

- Prague - Amsterdam (Europanet EMPB, the Netherlands, $64 \mathrm{~kb} / \mathrm{s}$ )

- Liberec - Zittau (DFN, Germany, $64 \mathrm{~kb} / \mathrm{s}$ )

- Prague - Banská Bystrica (SANET, Slovakia, $64 \mathrm{~kb} / \mathrm{s}$ ).

In addition to the usual services (E-mail, Telnet, FTP, etc.) for users of the CESNET there are available:

- Interconnected academic libraries

- Academic databases on publication activities

- Centralised distribution of Usenet news.

Details for the CESNET, may be finded in the text from Mr. J. Gruntorád, the CESNET project manager, on the e-mail address gopher.feld.cvut.cz (147.32.192.5).

Building the basic computer infrastructure in the Czech Republic was a very significant step in making the latest information technologies available to the academic community and developing reliable interactive information services.

This infrastructure is of course used for the purpose of the State Information system in the educational sphere. All statistical and economic data from 104 university facultics are collected, with few exceptions (less than $10 \%$ ), by means of the CESNET network. Some of the 85 local school authorities also use CESNET directly; alternativcly they can use the dial-up connection in their nearest CESNET node. The network is also accessiblc from EUROTEL.25 Public Data Network. But for the data transfer to local educational authorities for the primary and secondary education level, a floppy disks as a transfer media are still in common use, because of problems with the national telephone network reliability. 


\section{CONCLUSION}

New educational laws are in the stage of evolution and new arrangement of regions and districts is being prepared. New laws obviously will interfere with cducational management. Therefore the educational information and management system should be as flexible as possible and we shall have to wait before we can makc ccrtain decisions.

We must conclude that organisational problems in dealing with the collection and verification of data from schools and local authorities for the educational component of the State Information System are still very serious, comparable to hardware and softwarc networking problems accompanying the data transfer. The CESNET offres realistic improvement in educational management in our country. But the fundamental issue is to clarify information needs, data flows, and necessary time periodicity for all data that are useful for the educational information and management system, and to define data standards and interfaces.

One idea which may help to keep the consistency of central government necds and the maximal possible independence of schools may be to use networking not only for sending messages and data, and for sharing programs, but also for distributed processing. More complicated objects such as whole transactions can be mailed using the network. One software package based on this idea is presently being developed.

\section{REFERENCE}

1. Who Has the World's Best Schools? (A new study reveals some surprising strengths and weaknesses), Newsweek, 1993, Dec. 12. 